\title{
Noninvasive PET Imaging of CDK4/6 Activation in Breast Cancer
}

\author{
Nicholas Ramos ${ }^{1}$, Jairo Baquero-Buitrago ${ }^{1}$, Zakia Ben Youss Gironda ${ }^{1}$, Youssef Zaim Wadghiri $^{1}$, Thomas Reiner $^{2-4}$, \\ Fernando E. Boada ${ }^{1}$, and Giuseppe Carlucci ${ }^{1}$ \\ ${ }^{I}$ Center for Advanced Imaging Innovation and Research $\left(C A I^{2} R\right)$, NYU School of Medicine, New York, New York; Center for \\ Biomedical Imaging, Department of Radiology, NYU School of Medicine, New York, New York; ${ }^{2}$ Department of Radiology, Weill \\ Cornell Medical College, New York, New York; ${ }^{3}$ Department of Radiology, Memorial Sloan Kettering Cancer Center, New York, \\ New York; and ${ }^{4}$ Chemical Biology Program, Memorial Sloan Kettering Cancer Center, New York, New York
}

The cell cycle is a progression of 4 distinct phases (G1, S, G2, and $M)$, with various cycle proteins being essential in regulating this process. We aimed to develop a radiolabeled cyclin-dependent kinase 4/6 (CDK4/6) inhibitor for breast cancer imaging. Our transfluorinated analog $\left({ }^{18} \mathrm{~F}-\mathrm{CDKi}\right)$ was evaluated and validated as a novel PET imaging agent to quantify CDK4/6 expression in estrogen receptor (ER)-positive human epidermal growth factor receptor 2 $\left(\mathrm{HER}_{2}\right)$-negative breast cancer. Methods: ${ }^{18} \mathrm{~F}-\mathrm{CDKi}$ was synthesized and assayed against CDK4/6 kinases. ${ }^{18} \mathrm{~F}-\mathrm{CDKi}$ was prepared with a 2-step automated synthetic strategy that yielded the final product with remarkable purity and molar activity. In vitro and in vivo biologic specificity was assessed in a MCF-7 cell line and in mice bearing MCF-7 breast tumors. Nonradioactive palbociclib was used as a blocking agent to investigate the binding specificity and selectivity of ${ }^{18} \mathrm{~F}-\mathrm{CDK}$. Results: ${ }^{18} \mathrm{~F}-\mathrm{CDKi}$ was obtained with an overall radiochemical uncorrected yield of $15 \%$ and radiochemical purity higher than $98 \%$. The total time from the start of synthesis to the final injectable formulated tracer is $70 \mathrm{~min}$. The retention time reported for ${ }^{18} \mathrm{~F}-\mathrm{CDKi}$ and ${ }^{19} \mathrm{~F}-\mathrm{CDKi}$ is $27.4 \mathrm{~min}$ as demonstrated by coinjection with ${ }^{19} \mathrm{~F}-\mathrm{CDKi}$ in a high-pressure liquid chromatograph. In vivo blood half-life (weighted, $7.03 \mathrm{~min}$ ) and octanol/ water phase partition coefficient $(1.91 \pm 0.24)$ showed a mainly lipophilic behavior. ${ }^{18} \mathrm{~F}-\mathrm{CDKi}$ is stable in vitro and in vivo $>98 \%$ at $4 \mathrm{~h}$ after injection) and maintained its potent targeting affinity to CDK4/6. Cellular uptake experiments performed on the MCF-7 breast cancer cell line (ER-positive and $\mathrm{HER}_{2}$-negative) demonstrated specific uptake with a maximum intracellular concentration of about $65 \%$ as early as $10 \mathrm{~min}$ after incubation. The tracer uptake was reduced to less than $5 \%$ when cells were coincubated with a molar excess of palbociclib. In vivo imaging and ex vivo biodistribution of ER-positive, $\mathrm{HER}_{2}$-negative MCF-7 breast cancer models showed a specific uptake of approximately $4 \%$ injected dose/g of tumor (reduced to $\sim 0.3 \%$ with a 50 -fold excess of cold palbociclib). A comprehensive biodistribution analysis also revealed a significantly lower activation of CDK4/6 in nontargeting organs. Conclusion: ${ }^{18} \mathrm{~F}-\mathrm{CDKi}$ represents the first ${ }^{18} \mathrm{~F}$ PET CDK4/6 imaging agent and a promising imaging agent for ER-positive, $\mathrm{HER}_{2}-$ negative breast cancer.

Received Jun. 18, 2019; revision accepted Aug. 19, 2019.

For correspondence or reprints contact: Giuseppe Carlucci, Department of Radiology, NYU School of Medicine, 660 First Ave., New York, NY 10016.

E-mail: giuseppe.carlucci@nyulangone.org

Published online Sep. 3, 2019.

COPYRIGHT (C 2020 by the Society of Nuclear Medicine and Molecular Imaging.
Key Words: cell cycle; CDK4/6; PET/CT imaging; breast cancer; MCF-7

J Nucl Med 2020; 61:437-442

DOI: 10.2967/jnumed.119.232603

$\mathbf{T}$ he cell cycle is a progression of 4 distinct phases (G1, S, G2, and $\mathrm{M}$ ) that cells use to maintain the integrity of their genomes (1-5). Sophisticated cell cycle pathways and cell cycle arrest proteins are used to remediate DNA damage, efficiently control the cell cycle and DNA replication $(5,6)$, and trigger DNA repair. Alterations in the cell cycle and uncontrolled proliferation are wellknown hallmarks of cancer $(7,8)$. Cyclin-dependent kinases $4 / 6$ (CDK4/6) are 2 apical kinases that control the cell cycle by arresting the progression in case of DNA damage (9-12). Subsequent to cell damage, the cyclin D1 (cycD1)-CDK4/6 complex arrests the cell cycle progression in G1 to limit the proliferation of the DNA-damaged cells (13). Dysregulation of the cycD1-CDK4/6 axis appears to be an early step in cancer pathogenesis, and cycD1 overexpression is shown as early as ductal carcinoma in both in situ and metastatic lesions (7,13-17). Notably, amplification of genes encoding D-type cyclins is commonly observed in human cancer and correlates with increased levels of cyclin D protein. A major target of CDK4 and CDK6 during cell cycle progression is the retinoblastoma protein. CDK4/6-cycD1 complexes phosphorylate retinoblastoma. When retinoblastoma is phosphorylated, it dissociates from the E2F family, which enables cell cycle progression to the $\mathrm{S}$ phase. Selective inhibitors act on CDK4/6 kinases, dephosphorylate retinoblastoma, and stall the cell cycle progression in G1. This action inhibits the proliferation of cancer cells and triggers the DNA-damage repair. Hence, it is intuitive that efficient inhibition of CDK4/6 can enhance and amplify the chemotherapeutic effects of therapies aimed at targeting the cell cycle proliferation, checkpoints, and arrest.

Amplification of CDK4/6 and cycD1 has been reported in a significant number of cancers, and overexpression of cycD1 was observed in more than $60 \%$ of all breast cancers $(14,18-20)$. Furthermore, amplification and overexpression of cycD1 and CKD4/6 has been described in patients with head and neck cancer (21), non-small cell lung cancer (22), melanoma (23-25), and glioblastoma (26). Gene amplification of cycD1 was found to be most frequent in luminal $\mathrm{A}$, luminal $\mathrm{B}$, and human epidermal growth 
factor receptor $2\left(\mathrm{HER}_{2}\right)$-enriched breast cancer subtypes (frequencies of alteration: $29 \%, 58 \%$, and $38 \%$, respectively) (7). Similarly, amplifications of CDK4/6 were more common in the luminal A, luminal B, and $\mathrm{HER}_{2}$-enriched subgroups $(14 \%, 25 \%$, and $24 \%$, respectively) (7). Moreover, in patients with luminal estrogen receptor (ER)-positive breast cancer, which represents approximately $75 \%$ of all breast cancers, cycD1-CDK4/6 is expressed at a high level (15). Thus, ER-positive, luminal breast cancer is the typical and the most indicated model for investigating the effectiveness of CDK4/6 inhibitors and served as a platform for our initial biologic evaluation (7).

We developed ${ }^{18} \mathrm{~F}-\mathrm{CDKi}$, a PET-radiolabeled version of palbociclib (Ibrance; Pfizer) to noninvasively image kinase expression in breast cancer models. Specifically, we introduced an ${ }^{18} \mathrm{~F}$ prosthetic group $\left({ }^{18} \mathrm{~F}\right.$-fluorobenzoic acid) on the terminal piperazine (27) and synthesized a novel PET-active functional molecule. We aimed to determine whether ${ }^{18} \mathrm{~F}-\mathrm{CDKi}$ has suitable pharmacokinetic properties for noninvasive PET imaging and whether the tracer is selective for CDK4/6. For both in vitro and in vivo evaluation, a breast cancer ER-positive, $\mathrm{HER}_{2}$-negative cell line (MCF-7) was used.

To our knowledge, this is a first-in-class radiolabeled inhibitor able to target specifically CDK4/6. Because of these promising results in mouse models, we anticipate ${ }^{18} \mathrm{~F}-\mathrm{CDKi}$ to have a high prognostic value for tumor imaging and treatment response monitoring.

\section{MATERIALS AND METHODS}

\section{Materials}

No-carrier-added ${ }^{18} \mathrm{~F}$-fluoride was produced by the $(\mathrm{p}, \mathrm{n})$ reaction of ${ }^{18} \mathrm{O}-\mathrm{H}_{2} \mathrm{O}$ in an RDS-112 cyclotron (Siemens). Potassium carbonate, Kryptofix, ethyl 4-nitrobenzoate, $N, N, N^{\prime}, N^{\prime}$-tetramethyl- $O$-( $1 H$-benzotriazol-1-yl)uronium hexafluorophosphate (HBTU), triethylamine, ammonium formate, sodium hydroxide, hydrochloric acid, acetonitrile, and dimethyl sulfoxide were purchased from Millipore-Sigma and used without further purification unless otherwise stated. Palbociclib hydrochloride was purchased from Selleck. Adenosine triphosphate was obtained from PerkinElmer. Ethanol was purchased from Thermo Fisher. Sep-Pak Accell Plus quaternary methyl ammonium and C18 Sep-Pak cartridges were purchased from Waters. Semipreparative high-pressure liquid chromatography (HPLC) was conducted in a TRACERlab FX2N (GE Healthcare) under the following HPLC conditions: Phenomenex Gemini C6 phenyl column $(10 \times 250 \mathrm{~mm}, 10 \mu \mathrm{m})$; mobile phase, $64 \% 75 \mathrm{mM}$ ammonium fluoride and $36 \% \mathrm{MeCN} ; 5 \mathrm{~mL} / \mathrm{min}$ (method A). Analytic HPLC was performed using a Shimadzu binary LC-20AR HPLC gradient pump with an inline SPD-20A variable wavelength ultraviolet/visible-light detector and a flow count unit with a PMT detector using a Phenomenex C6 Gemini reverse-phase column $(4.6 \times 250 \mathrm{~mm}, 5 \mu \mathrm{m})$ with a mobile phase of $64 \% 75 \mathrm{mM}$ ammonium fluoride and $36 \% \mathrm{MeCN}$ at a rate of $2 \mathrm{~mL} / \mathrm{min}$ (method B). Analytic chromatograms were collected by an analog-todigital converter using Lab Solutions software. Preparative and analytic HPLC analyses of ${ }^{18} \mathrm{~F}$-labeled compounds were calibrated with the corresponding ${ }^{19} \mathrm{~F}$ analogs. Radioactivity in blood half-life, cell uptake, and biodistribution studies was quantified with a WIZARD ${ }^{2}$ automatic $\gamma$-counter (PerkinElmer). All in vivo experiments were carried out with Inveon PET/CT (Siemens Medical Solutions) and reconstructed using Inveon Research (Siemens Medical Solutions). All ${ }^{18} \mathrm{~F}$ and ${ }^{19} \mathrm{~F}$ CDKi final products were formulated in $10 \%$ ethanol/ $90 \%$ saline $(0.9 \%)$.

\section{Cell Culture}

Phosphate-buffered saline and Dulbecco modified Eagle medium were purchased from Thermo Fisher. MCF-7, a human ER-positive,
$\mathrm{HER}_{2}$-negative breast cancer cell line, was purchased from ATCC. Dulbecco modified Eagle medium contained $10 \%(\mathrm{v} / \mathrm{v})$ heat-inactivated fetal bovine serum, $100 \mathrm{IU}$ penicillin, and a $100 \mu \mathrm{g} / \mathrm{mL}$ concentration of streptomycin.

\section{Mouse Model}

Female athymic nude CrTac:NCr-Foxn1nu mice $(n=35)$ were purchased from Taconic Laboratories. Twenty mice received subcutaneous injections with $2 \times 10^{6}$ human MCF-7 cancer cells in Matrigel (BD Biosciences) into each right shoulder and were allowed to grow for approximately 2 mo until the tumors reached about $10 \mathrm{~mm}$ in diameter. All mice were supplemented with a 0.72-mg slow-release estradiol pellet (left for $60 \mathrm{~d}$ ) implanted in the left flank (Innovative Research of America, Sarasota, FL). Mice were anesthetized (isoflurane, $1.5 \%$; $2 \mathrm{~L} / \mathrm{min}$ flow of medical air) during tumor implantation and smallanimal PET imaging.

Fifteen mice were used for blood half-life measurements and in vivo stability studies. All animal experiments were conducted in accordance with protocols approved by the Institutional Animal Care and Use Committee of NYU Langone Health and followed National Institutes of Health guidelines for animal welfare.

\section{Preparation of ${ }^{19} \mathrm{~F}-\mathrm{CDKi}$}

To a solution of palbociclib in dimethylsulfoxide $(20 \mathrm{mg}, 0.04 \mathrm{mmol})$, fluorobenzoic acid (15 mg, $0.1 \mathrm{mmol}$ ), HBTU (45 mg, $0.1 \mathrm{mmol}$ ), and triethylamine $(12 \mathrm{mg}, 0.1 \mathrm{mmol})$ were added and the solution reacted at $37^{\circ} \mathrm{C}$ for $24 \mathrm{~h}$. The resulting solution was filtered and purified by reverse-phase HPLC to the desired derivative (yield, 70\%), dried, and lyophilized to yield the final product. Electrospray ionization mass spectrometry spectra were recorded with a Shimadzu LC-2020 with electrospray ionization single-quad detector.

\section{Radiochemistry}

No-carrier-added ${ }^{18} \mathrm{~F}$-fluoride was obtained via the ${ }^{18} \mathrm{O}(\mathrm{p}, \mathrm{n}){ }^{18} \mathrm{~F}$ nuclear reaction of $11-\mathrm{MeV}$ protons in an RDS Eclipse (Siemens Medical Solutions). Synthesis was automated using an FX2N module (GE Healthcare). Briefly, a quaternary methyl ammonium cartridge containing cyclotron-produced ${ }^{18} \mathrm{~F}$-fluoride ion was eluted with a solution containing $9 \mathrm{mg}$ of Kryptofix [2.2.2] (4,7,13,16,21,24-hexaoxa1,10-diazabicyclo[8.8.8]hexacosane), $0.08 \mathrm{~mL}$ of $0.15 \mathrm{M} \mathrm{K}_{2} \mathrm{CO}_{3}$, and 1.92 $\mathrm{mL}$ of $\mathrm{MeCN}$ into a $5-\mathrm{mL}$ reaction vial. Water was removed azeotropically at $120^{\circ} \mathrm{C}$. One milligram of ethyl-4-nitrobenzoate was dissolved in $300 \mu \mathrm{L}$ of dimethylsulfoxide and added to the reaction vial, heated to $150^{\circ} \mathrm{C}$ for $15 \mathrm{~min}$, and then cooled to room temperature. Afterward, $150 \mu \mathrm{L}$ of $1 \mathrm{M} \mathrm{NaOH}$ were added. The reaction mixture was stirred for $1 \mathrm{~min}$, and $150 \mu \mathrm{L}$ of $1 \mathrm{M} \mathrm{HCl}$ were added to quench. Then, $2 \mathrm{mg}$ of palbociclib dissolved in $200 \mu \mathrm{L}$ of dimethylsulfoxide were added, followed by $10 \mathrm{mg}$ of HBTU dissolved in $200 \mu \mathrm{L}$ of dimethylsulfoxide and $30 \mu \mathrm{L}$ of $\mathrm{Et}_{3} \mathrm{~N}$. MeCN (400 $\left.\mu \mathrm{L}\right)$ followed by $700 \mu \mathrm{L}$ of $\mathrm{H}_{2} \mathrm{O}$ was then added, and the solution was injected onto a C6-phenyl analytic HPLC column and eluted under isocratic conditions. Then, the collected fraction was passed through a C18 light-SepPak cartridge and ${ }^{18} \mathrm{~F}-\mathrm{CDKi}$ was eluted using $\mathrm{EtOH}(400 \mu \mathrm{L})$. The solution was then diluted with $0.9 \%$ saline to $10 \% \mathrm{EtOH}$. Molar activity was determined by dividing the activity present in the final formulated product $(\mathrm{GBq})$ by the material remaining in the formulated product after purification (moles) and was determined using an ultraviolet calibration curve $(\lambda=254 \mathrm{~nm})$.

\section{Chemical Hydrophobicity Index and Octanol/Water Partition Coefficient}

The chemical hydrophobicity indices were measured using a previously developed procedure $(28,29)$. Briefly, reverse-phase HPLC was used to measure the retention times of a set of standards with known chemical hydrophobicity index. A standard curve was then 
created to calculate the chemical hydrophobicity index of ${ }^{19} \mathrm{~F}-\mathrm{CDKi}$ based on the HPLC retention time. The lipophilicity of the ${ }^{18} \mathrm{~F}-\mathrm{CDKi}$ was acquired by adding $0.09 \mathrm{MBq}$ to a mixture of $0.5 \mathrm{~mL}$ of 1-octanol and $0.5 \mathrm{~mL}$ of $25 \mathrm{mM}$ phosphate-buffered saline ( $\mathrm{pH} \mathrm{7.4)}$ and mixed for $5 \mathrm{~min}$. Then, the mixture was centrifuged at 15,000 rpm for $5 \mathrm{~min}$. Samples $(100 \mu \mathrm{L})$ were obtained from organic and aqueous layers, and the radioactivity of the samples was measured in a WIZARD ${ }^{2}$ automatic $\gamma$-counter. The experiment was performed in triplicate, and the resulting octanol-water partition coefficient was calculated as the mean $\pm \mathrm{SD}$.

\section{Blood Half-Life}

The blood half-life of ${ }^{18} \mathrm{~F}-\mathrm{CDKi}$ was calculated by measuring the activity of blood samples collected at different time points after injection $(5,15,30,45,60,90$, and $120 \mathrm{~min})$. Female nude mice $(n=3)$ were injected via the lateral tail vein with ${ }^{18} \mathrm{~F}-\mathrm{CDKi}$, and blood samples were obtained by a retroorbital bleed using tared capillary tubes. Samples were weighed, and activity was measured by $\gamma$-counter. The blood half-life was calculated by Prism 7 (GraphPad Software) using a 2-phase decay least-squares fitting method and expressed as percentage injected dose (\%ID)/g.

\section{In Vivo and Ex Vivo Blood Stability}

${ }^{18} \mathrm{~F}-\mathrm{CDKi}$ (7.4 MBq) was injected in healthy athymic nude mice $(n=15)$ via tail injection. The mice were killed at different time points $(0,60,120,180$, and $240 \mathrm{~min}$ after injection), and blood was collected. MeCN $(750 \mu \mathrm{L})$ was added to the collected blood and then centrifuged ( $5 \mathrm{~min}$ at 5,000 rpm) to pellet blood cells and proteins. The supernatant was collected, diluted with $750 \mu \mathrm{L}$ of $\mathrm{H}_{2} \mathrm{O}$, and injected onto an HPLC column. The blood stability was measured by HPLC analysis (method B).

\section{Half-Maximal Inhibitory Concentration $\left(\mathrm{IC}_{50}\right)$ Binding Affinity and Competitive Inhibitory Displacement}

$\mathrm{IC}_{50}$ values were determined using a competitive adenosine triphosphate quantitative assay as reported elsewhere (30) and ${ }^{19} \mathrm{~F}-\mathrm{CDKi}$. MCF-7 cells were cultured at $37^{\circ} \mathrm{C}$ for $4 \mathrm{~h}$. Then, ${ }^{19} \mathrm{~F}-\mathrm{CDKi}$ or vehicle was added at different concentrations and incubated at $37^{\circ} \mathrm{C}$ for $96 \mathrm{~h}$. Cell viability was then assessed using a CellTiter-Glo Luminescent Assay (Promega), according to the manufacturer's guidelines. Cell viability inhibition (\%) was calculated according to the formula [1 - (mean luminosity of treated sample/mean luminosity of vehicle control) $] \times 100$. The $\mathrm{IC}_{50}$ for growth or viability inhibition was calculated using Prism 8 . We also used ${ }^{18} \mathrm{~F}-\mathrm{CDKi}$ and palbociclib for competitive displacement studies. MCF-7 cells were seeded in a 12 -well plate $\left(1 \times 10^{5}\right.$ cells $24 \mathrm{~h}$ before the experiment $)$. The next day, a fixed concentration of ${ }^{18} \mathrm{~F}-\mathrm{CDKi}(50 \mathrm{nM})$ was coincubated with linearly doubling concentrations of palbociclib (from 0 to 500 $\mathrm{nM})$ at $37^{\circ} \mathrm{C}$ for $2 \mathrm{~h}$. Then, the cells were washed twice with phosphate-buffered saline and lysed with $1 \mathrm{~N} \mathrm{NaOH}$, and the activity $(\mathrm{cpm})$ was measured in a $\gamma$-counter for bound ${ }^{18} \mathrm{~F}$ radioligand. The percentage of bound radioligand was finally plotted against palbociclib concentration. Competitive displacement curves were fitted using Prism 8.

\section{In Vitro Uptake}

MCF-7 cells were seeded in a 6 -well plate $\left(5 \times 10^{6}\right.$ cells $24 \mathrm{~h}$ before the experiment). The next day, ${ }^{18} \mathrm{~F}$-CDKi was added alone or together with a 50-fold excess of palbociclib and incubated at $37^{\circ} \mathrm{C}$ for $1 \mathrm{~h}$. After $1 \mathrm{~h}$, cells were first washed 3 times with phosphate-buffered saline and then lysed with $1 \mathrm{~N} \mathrm{NaOH}$, and finally the medium and cells were counted in a $\gamma$-counter. The percentage of bound-to-unbound radioligand at each time point was measured in triplicate and plotted as a function of time.

\section{Small-Animal PET/CT Imaging}

Twelve subcutaneous MCF-7 implanted athymic nude mice were divided into 2 groups (blocked and ${ }^{18} \mathrm{~F}-\mathrm{CDKi}$ ) and administered ${ }^{18} \mathrm{~F}$ $\mathrm{CDKi}(\sim 7.4 \mathrm{MBq})$ via tail vein injection. Approximately $5 \mathrm{~min}$ before PET acquisition, the mice were anesthetized by inhalation of a mixture of isoflurane ( $2 \%$ isoflurane, $2 \mathrm{~L} / \mathrm{min}$ flow of medical air; Baxter Healthcare) and positioned in the scanner. Anesthesia was maintained using a $1 \%$ isoflurane $/ \mathrm{O}_{2}$ mixture. PET data for each mouse were recorded and acquired at 30 and $120 \mathrm{~min}$ after injection. Blocking studies were performed after preinjection of a 50-fold excess of palbociclib ( $8.4 \mathrm{nmol}, 3.8 \mu \mathrm{g}, 30 \mathrm{~min}$ beforehand). The PET/CT sessions were $20 \mathrm{~min}$ each.

\section{Biodistribution}

The biodistribution of ${ }^{18} \mathrm{~F}-\mathrm{CDKi}$ was determined in subcutaneous MCF-7-bearing athymic nude mice $(n=8)$. The mice were divided into blocked and unblocked groups ( $n=4$ /group) (50-fold excess of palbociclib, $2 \mathrm{nmol}, 0.95 \mu \mathrm{g}, 30 \mathrm{~min}$ beforehand) and administered ${ }^{18} \mathrm{~F}-\mathrm{CDKi}$ via tail vein injection $(1.85 \mathrm{MBq})$. At $120 \mathrm{~min}$ after injection of the radioligand, the mice were killed and organs of interest were collected. Organs were weighed, and activity was measured with a WIZARD ${ }^{2}$ automatic $\gamma$-counter. Radiopharmaceutical uptake was expressed as \%ID/g using the following formula: [(activity in the target organ/grams of tissue)/injected dose] $\times 100 \%$.

\section{Statistical Analysis}

All data are expressed as mean \pm SD. Differences between mouse cohorts were analyzed with the 2-tailed unpaired Student $t$ test and were considered statistically significant when the $P$ value was less than 0.05 .

\section{RESULTS}

\section{Chemistry and Radiochemistry}

${ }^{18} \mathrm{~F}-\mathrm{CDKi}$ was synthesized by a 2 -step method (Fig. 1A; Supplemental Fig. 1 [supplemental materials are available at http:// jnm.snmjournals.org]). The final ${ }^{18} \mathrm{~F}$ transfluorinated product (Fig. 1B) was obtained with an overall uncorrected yield of about $15 \%$ $(n=4)$ and a radiochemical purity of more than $98 \%$. Molar activity was $44 \mathrm{GBq} / \mu \mathrm{mol}$, and the total automated synthesis time was $80-90 \mathrm{~min}$. The retention time reported for ${ }^{18} \mathrm{~F}-\mathrm{CDKi}$ and ${ }^{19} \mathrm{~F}-\mathrm{CDKi}$ was about $17 \mathrm{~min}$ as demonstrated by coinjection with ${ }^{19} \mathrm{~F}-\mathrm{CDKi}$ on an HPLC column (Fig. 1C). ${ }^{19} \mathrm{~F}-\mathrm{CDKi}$ (Fig. 2A; final yield, $\sim 80 \%$ ) was obtained with high purity as shown by liquid chromatography-mass spectrometry. The observed mass-tocharge ratio for ${ }^{19} \mathrm{~F}-\mathrm{CDKi}$ was $566([\mathrm{M}]+\mathrm{H})$ and $564([\mathrm{M}]-\mathrm{H})$ in positive- and negative-polarity mode (expected mass-to-charge ratio for $\left.{ }^{19} \mathrm{~F}-\mathrm{CDKi}, 565\right)$ (Supplemental Fig. 2B). No unreacted palbociclib (molecular weight, $447.5 \mathrm{~g} / \mathrm{mol}$ ) was observed after purification, indicating a high chemical purity of the HPLC-purified ${ }^{19} \mathrm{~F}-\mathrm{CDKi}$.

\section{Cellular Binding Specificity and Cell Internalization}

${ }^{18} \mathrm{~F}-\mathrm{CDKi}$ maintained a potent targeting affinity to CDK4/6 $(\sim 13 \mathrm{nM})$ (Fig. 2A). The competitive displacement of palbociclib in MCF-7 cells was an indication that ${ }^{18} \mathrm{~F}-\mathrm{CDKi}$ had an inhibition effect similar to that of ${ }^{19} \mathrm{~F}-\mathrm{CDKi}(\sim 18 \mathrm{nM})$ in MCF-7 cells (Supplemental Fig. 3). Cell-associated uptake of ${ }^{18} \mathrm{~F}-\mathrm{CDKi}$ is shown in Supplemental Figure 4. Cell uptake could be blocked nearly completely $(>98 \%)$ by the addition of an excess of cold, unlabeled palbociclib $(P<0.0001)$, suggesting the high cellular specificity of ${ }^{18} \mathrm{~F}-\mathrm{CDKi}$. Cellular uptake experiments performed on the MCF-7 breast cancer cell line (ER-positive and $\mathrm{HER}_{2}$-negative) demonstrated a maximum intracellular concentration of about 


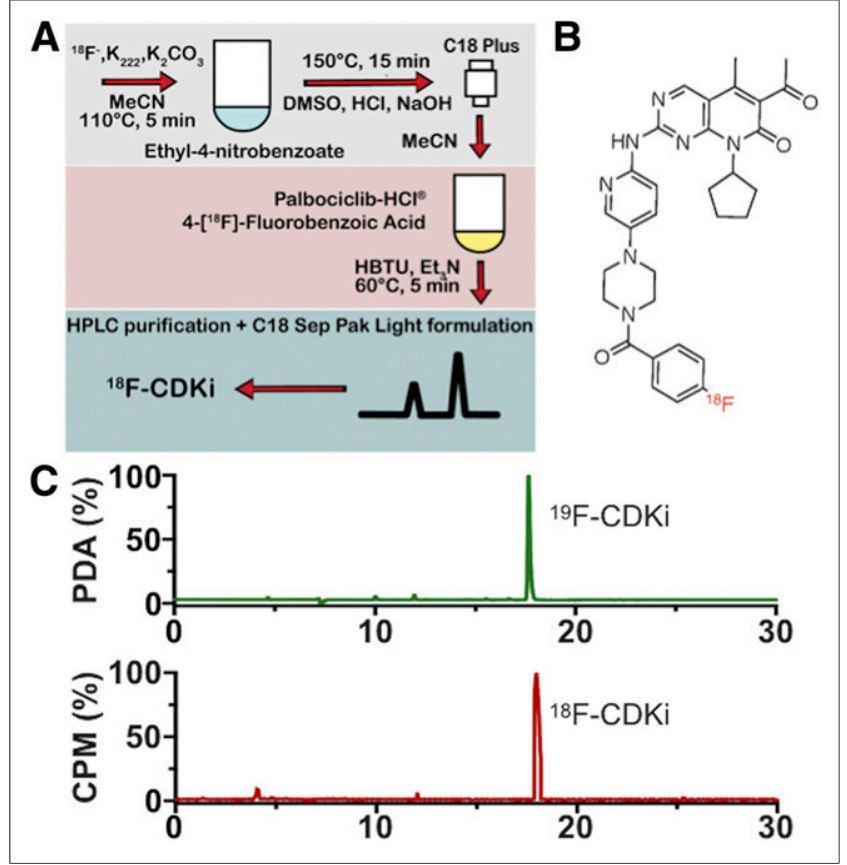

FIGURE 1. (A) ${ }^{18} \mathrm{~F}-\mathrm{CDKi}$ radiochemistry and production method. (B) Chemical structure of ${ }^{18} \mathrm{~F}-\mathrm{CDKi}$. (C) Chromatograms representing coinjection of ${ }^{18} \mathrm{~F}-\mathrm{CDKi}$ with ${ }^{19} \mathrm{~F}-\mathrm{CDKi}$ and showing successful synthesis and purity of PET tracer. PDA = photometric diode array.

$65 \%$ already at $10 \mathrm{~min}$ after incubation, when the internalization rate plateaued.

\section{Stability and Pharmacokinetics}

The in vivo blood half-life (weighted) was $7.03 \mathrm{~min}$ (Fig. 2B). ${ }^{18} \mathrm{~F}-\mathrm{CDKi}$ was stable both in vitro and in vivo, with more than $98 \%$ of the parent compound intact after $4 \mathrm{~h}$ of incubation $(>98 \%$ at $4 \mathrm{~h}$ after injection). The octanol-to-water phase partition coefficient was $1.91 \pm 0.24$, and the chemical hydrophobicity index was 61.23 (Figs. 2C-2E).

\section{In Vivo Imaging and Ex Vivo Biodistribution}

PET imaging showed a significant specific uptake in the tumor lesion (Fig. 3). MCF-7 xenografts showed approximately $4 \%$ ID/g when mice were injected with ${ }^{18} \mathrm{~F}-\mathrm{CDKi}$. Tracer uptake in the tumor decreased to about $0.3 \% \mathrm{ID} / \mathrm{g}$ when mice were blocked with a 50-fold excess of palbociclib. PET imaging and biodistribution data showed that ${ }^{18} \mathrm{~F}-\mathrm{CDKi}$ was cleared via the hepatobiliary route (Figs. 3 and 4A). A high concentration of ${ }^{18} \mathrm{~F}-\mathrm{CDKi}$ was found in the kidneys $(7.99 \pm 0.7$ or $9.6 \pm 0.98 \% \mathrm{ID} / \mathrm{g})$, liver $(6 \pm 0.5$ or $6.77 \pm 1.15 \% \mathrm{ID} / \mathrm{g})$, and small intestines $(9.6 \pm 2.7$ or $10 \pm 1.19$ $\% \mathrm{ID} / \mathrm{g}$ ), with relatively low distribution in other tissues (Fig. 4A) at $2 \mathrm{~h}$ after injection. A statistically significant difference in uptake was obtained in the tumor (Fig. 4B). A comprehensive biodistribution analysis also revealed remarkable tumor-to-blood $(>5)$, tumor-to-muscle $(>15)$, and tumor-to-bone $(>10)$ ratios (Fig. $4 C)$. A complete dataset showing a favorable in vivo pharmacokinetic profile for ${ }^{18} \mathrm{~F}-\mathrm{CDKi}$ is available in Supplemental Figure 5.

\section{DISCUSSION}

In this article, we present the first report on an in vivo CDK4/6 imaging agent with strong similarities to palbociclib, the first clinically Food and Drug Administration-approved CDK4/6 inhibitor (31).

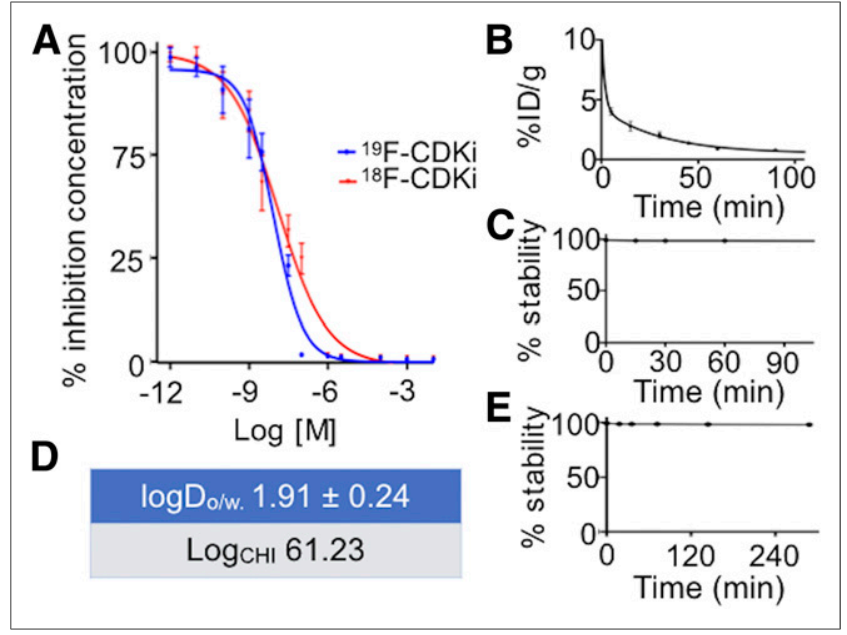

FIGURE 2. (A) ${ }^{18} \mathrm{~F}-\mathrm{CDKi} /{ }^{19} \mathrm{~F}-\mathrm{CDKi}$ shows nanomolar binding affinity to CDK4/6. (B-E) ${ }^{18} \mathrm{~F}-\mathrm{CDKi}$ displays 7 -min blood half-life (B), high in vitro and in vivo stability $(C$ and $D)$, and lipophilic behavior $(E)$. $\log _{C H I}=$ chromatography hydrophobicity index; $\log \mathrm{D}_{\mathrm{o} / \mathrm{w}}=$ octanol/water phase partition coefficient.

CDK4/6 inhibitors are being intensively studied, and several clinical trials were established to study the effects of various compounds in synthetic lethal combination settings $(14,32,33)$. A common characteristic to those treatments is the development of resistance $(32,34,35)$. Poor oral availability, poor clearance and metabolism, biological feedback from other cyclins, and lack of target enzyme are all hypotheses for innate and acquired resistance to CDK4/6 inhibitors (34). However, none of the potential resistance mechanisms demonstrated in preclinical settings could be further confirmed in clinical studies (32-34). For this reason, we synthesized a radioligand that can reveal whether the drug accumulation in the tumor is limiting the therapeutic efficiency. ${ }^{18} \mathrm{~F}$-CDKi might help to select patient responders or nonresponders to CDK4/6 inhibitors. ${ }^{18} \mathrm{~F}-\mathrm{CDKi}$ might assess whether CDK or palbociclib treatment

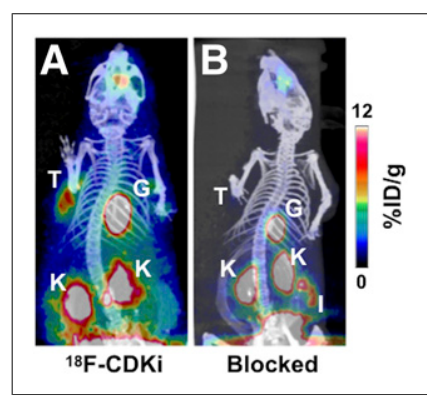

FIGURE 3. In vivo small-animal PET/CT images of MCF-7-bearing mouse models. (A) Single-bolus injection of ${ }^{18} \mathrm{~F}$-CDKi $(7.4 \mathrm{MBq}$ acquired at $2 \mathrm{~h}$ after injection). (B) Control MCF-7 mouse (preinjected with excess of palbociclib $30 \mathrm{~min}$ before ${ }^{18} \mathrm{~F}-\mathrm{CDKi}, 7.4 \mathrm{MBq}$, with image acquired $2 \mathrm{~h}$ after injection). Active areas in scans are nasal epithelium and Harderian glands, tumor $(T)$, gallbladder $(G)$, kidneys $(K)$, and intestines (I). combinations are well tolerated, even without an increase of febrile neutropenia, which is significantly more common in the palbociclib-containing combinations than in hormonal therapy alone. Moreover, ${ }^{18} \mathrm{~F}-\mathrm{CDKi}$ can indicate whether treatments necessitate dose interruptions and reductions. Finally, ${ }^{18} \mathrm{~F}-$ CDKi may allow the study of the pharmacodynamic effects of lower doses of palbociclib and thus help to tailor a specific line of treatment in ERpositive, $\mathrm{HER}_{2}$-negative breast cancer patients.

Structurally, the introduction of an ${ }^{18} \mathrm{~F}$ prosthetic synthon to the piperazine group appeared to be a viable approach for generating a labeled CDK4/6 


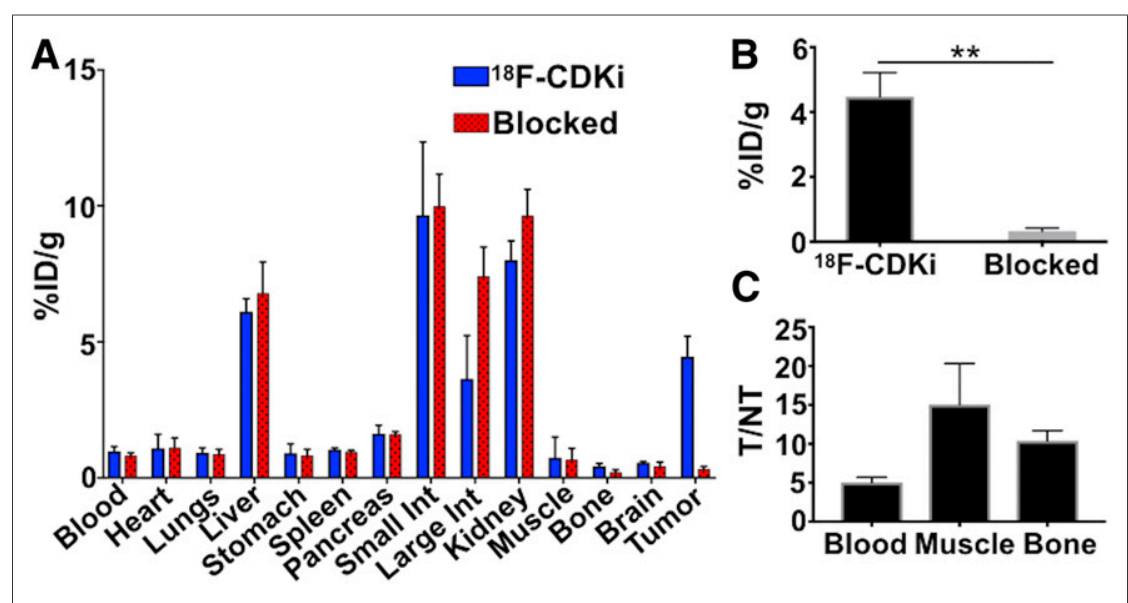

FIGURE 4. (A) Ex vivo biodistribution ( $2 \mathrm{~h}$ after injection) with single ${ }^{18} \mathrm{~F}-\mathrm{CDKi}$ injection or with preinjection of palbociclib (blocked). (B) Significance of tumor \% ID/g between ${ }^{18} \mathrm{~F}-\mathrm{CDKi}$ and blocked control group. (C) Tumor-to-nontarget (NT) ratio for blood, muscle, and bone $(n=4)$. ${ }^{\star \star} P<\cdots$. Int $=$ intestine.

\section{CONCLUSION}

${ }^{18} \mathrm{~F}-\mathrm{CDKi}$ combines high stability, fast penetration, high contrast, and rapid washout properties with a remarkable in vitro and in vivo binding to CDK4/6. These results suggest that this probe could offer an early prognostic assessment of treatment response or acquired resistance to $\mathrm{CDK} 4 /$ 6 inhibitors. Moreover, with a hybrid imaging technique, such as PET ${ }^{18} \mathrm{~F}-\mathrm{CDKi}$ in combination with MRI, clinicians might have an alternative approach to tailor precise medical treatments and therapies on the basis of patient CDK4/6 biomarker expression.

\section{DISCLOSURE}

No potential conflict of interest relevant to this article was reported. inhibitor. First, we synthesized and profiled ${ }^{19} \mathrm{~F}-\mathrm{CDKi}$, the cold fluorinated analog of the radiolabeled counterpart. ${ }^{19} \mathrm{~F}-\mathrm{CDKi}$ was key to assessing whether the fluorobenzoic tag would affect the compound's biologic activity. ${ }^{18} \mathrm{~F}-\mathrm{CDKi}$ was readily synthesized using a modified published synthetic approach (36,37). Minor modifications for automation purposes were included as well. Synthesis started from conversion of 4-ethyl-nitrobenzoate to $4-{ }^{18} \mathrm{~F}$-fluorobenzoic acid. Subsequent reaction with palbociclib was rapidly accomplished in basic conditions to yield the final ${ }^{18} \mathrm{~F}-\mathrm{CDKi}$ imaging agent. After scale-up synthesis and characterization of the radiotracer, we next tested the radiolabeled tracer ${ }^{18} \mathrm{~F}-\mathrm{CDK}$ both in vitro and in vivo. In light of the relevance of palbociclib in treating ER-positive, $\mathrm{HER}_{2}$-negative breast cancer, we chose MCF-7 as a mouse model for our in vitro and in vivo studies.

Initially, we determined the in vivo blood half-life and plasma stability of ${ }^{18} \mathrm{~F}-\mathrm{CDK}$. The tracer displayed a specific intracellular uptake in MCF-7 cells and an $\mathrm{IC}_{50}$ in the nanomolar range, similar to the parent compound, palbociclib (27). The insertion of an ${ }^{18} \mathrm{~F}$ prosthetic group did not modify the binding properties of CDKi. Furthermore, like other CDK4/6 inhibitors, our molecule is also an adenosine triphosphate-competitive ligand of CDK4 and CDK6. Herein, as previously reported elsewhere, the $\mathrm{IC}_{50}$ is reported with single-digit nanomolar potency against both CDK4 and CDK6 kinases (38). The blood halflife, after a single-bolus intravenous injection, showed a biphasic pharmacokinetic profile with rapid elimination of ${ }^{18} \mathrm{~F}-\mathrm{CDKi}$ during the first $10 \mathrm{~min}$, similar to other small-molecule inhibitors $(37,39) .{ }^{18} \mathrm{~F}-\mathrm{CDKi}$ shows a marked lipophilic behavior, and more than $98 \%$ of the tracer was stable in vivo at $4 \mathrm{~h}$ after injection. In subcutaneous MCF-7 xenografts, ${ }^{18} \mathrm{~F}-\mathrm{CDKi}$ was rapidly washed out from nontarget organs, resulting in a remarkable ratio of tumor to nontarget tissue at $2 \mathrm{~h}$ after injection. Consistent with $\mathrm{CDKi}$ activation and cycD1 overexpression in breast tumors, ${ }^{18} \mathrm{~F}-\mathrm{CDKi}$ was observed to specifically accumulate in the tumor as proven by the blocking experiment. MCF-7-bearing mice that received an injection of palbociclib before the radiotracer showed negligible ${ }^{18} \mathrm{~F}-\mathrm{CDKi}$ tumor uptake. There is significant promise that more positive clinical outcomes will emerge through a detailed understanding of the biology of CDK4/6 inhibitors $(14,15,33)$.

This novel tracer might further be used as a tool to improve patients outcome or design more personalized combination strategies $(32,34)$.

\section{ACKNOWLEDGMENTS}

We thank the Education and Research Foundation for Nuclear Medicine and Molecular Imaging (2017 ERF-SNMMI for Giuseppe Carlucci) for its generous support. This work was supported by National Institutes of Health grants P41 EB017183 (Fernando Boada and Giuseppe Carlucci) and R01 CA204441 and P30 CA008748 (Thomas Reiner). We thank the Tow Foundation and MSK's Center for Molecular Imaging \& Nanotechnology and Imaging and Radiation Sciences Program.

\section{KEY POINTS}

QUESTION: Can ${ }^{18} \mathrm{~F}-\mathrm{CDKi}$ provide an exact and accurate assessment of functional CDK4/6 expression in breast cancer development and progression and be used to monitor CDK4/6based treatment?

PERTINENT FINDINGS: The first in vitro experiment aiming to analyze pharmacokinetics and in vitro activity revealed that ${ }^{18} \mathrm{~F}-\mathrm{CDKi}$ (based on palbociclib, a Food and Drug Administration-approved drug) can be a successful PET agent with nearly ideal imaging characteristics. We demonstrated that ${ }^{18} \mathrm{~F}-\mathrm{CDKi}$ is stable in vitro and in vivo and maintained a potent targeting affinity to CDK4/6. Cellular uptake experiments performed on a MCF-7 breast cancer cell line (ER-positive, $\mathrm{HER}_{2}$-negative) demonstrated specific uptake. Similar significant uptake values were also observed in MCF-7-bearing mouse models. The strong activation of CDK4/6 in cancer cells in concert with its low activation in untransformed healthy cells (as resulted from our tumorto-nontarget-tissue ratio calculations) makes ${ }^{18} \mathrm{~F}-\mathrm{CDKi}$ an ideal imaging agent, first in its class, for CDK4/6 assessment.

IMPLICATIONS FOR PATIENT CARE: ${ }^{8} \mathrm{~F}-\mathrm{CDKi}$ can improve screening for breast cancer and selection of responders to CDK4/ 6 therapy. ${ }^{18} \mathrm{~F}-\mathrm{CDKi}$ allows quantification of CDK4/6 activation (at a cellular level) and assessment of CDK4/6 protein status in current translational cancer research.

\section{REFERENCES}

1. Jackson SP, Helleday T. Drugging DNA repair. Science. 2016;352:1178-1179.

2. Da-Rè C, Halazonetis TD. DNA replication stress as an Achilles' heel of cancer. Oncotarget. 2015;6:1-2. 
3. Bartek J, Mistrik M, Bartkova J. Thresholds of replication stress signaling in cancer development and treatment. Nat Struct Mol Biol. 2012;19:5-7.

4. Jackson SP, Bartek J. The DNA-damage response in human biology and disease. Nature. 2009;461:1071-1078.

5. Kastan MB, Bartek J. Cell-cycle checkpoints and cancer. Nature. 2004;432:316-323.

6. Benada J, Macurek L. Targeting the checkpoint to kill cancer cells. Biomolecules. 2015;5:1912-1937.

7. Finn RS, Aleshin A, Slamon DJ. Targeting the cyclin-dependent kinases (CDK) 4/6 in estrogen receptor-positive breast cancers. Breast Cancer Res. 2016;18:17.

8. Hanahan D, Weinberg RA. Hallmarks of cancer: the next generation. Cell. 2011;144: 646-674.

9. Manic G, Obrist F, Sistigu A, Vitale I. Trial watch: targeting ATM-CHK2 and ATR-CHK1 pathways for anticancer therapy. Mol Cell Oncol. 2015;2:e1012976.

10. Weber AM, Ryan AJ. ATM and ATR as therapeutic targets in cancer. Pharmacol Ther. 2015;149:124-138.

11. Abraham RT. Cell cycle checkpoint signaling through the ATM and ATR kinases. Genes Dev. 2001;15:2177-2196.

12. Pleasance ED, Cheetham RK, Stephens PJ, et al. A comprehensive catalogue of somatic mutations from a human cancer genome. Nature. 2010;463:191-196.

13. Musgrove EA, Caldon CE, Barraclough J, Stone A, Sutherland RL. Cyclin D as a therapeutic target in cancer. Nat Rev Cancer. 2011;11:558-572.

14. Hamilton E, Infante JR. Targeting CDK4/6 in patients with cancer. Cancer Treat Rev. 2016;45:129-138

15. VanArsdale T, Boshoff C, Arndt KT, Abraham RT. Molecular pathways: targeting the cyclin D-CDK4/6 axis for cancer treatment. Clin Cancer Res. 2015;21:2905-2910.

16. Yu Q, Sicinska E, Geng Y, et al. Requirement for CDK4 kinase function in breast cancer. Cancer Cell. 2006;9:23-32.

17. Landis MW, Pawlyk BS, Li T, Sicinski P, Hinds PW. Cyclin D1-dependent kinase activity in murine development and mammary tumorigenesis. Cancer Cell. 2006;9:13-22.

18. Bartkova J, Lukas J, Muller H, Lutzhoft D, Strauss M, Bartek J. Cyclin D1 protein expression and function in human breast cancer. Int J Cancer. 1994;57: 353-361.

19. Dickson C, Fantl V, Gillett C, et al. Amplification of chromosome band 11q13 and a role for cyclin D1 in human breast cancer. Cancer Lett. 1995;90:43-50.

20. Yu Q, Geng Y, Sicinski P. Specific protection against breast cancers by cyclin D1 ablation. Nature. 2001;411:1017-1021.

21. Akervall JA, Michalides RJ, Mineta H, et al. Amplification of cyclin D1 in squamous cell carcinoma of the head and neck and the prognostic value of chromosomal abnormalities and cyclin D1 overexpression. Cancer. 1997;79:380-389.

22. Betticher DC, Heighway J, Hasleton PS, et al. Prognostic significance of CCND1 (cyclin D1) overexpression in primary resected non-small-cell lung cancer. $\mathrm{Br} \mathrm{J}$ Cancer. 1996;73:294-300.
23. Bleeker FE, Lamba S, Rodolfo M, et al. Mutational profiling of cancer candidate genes in glioblastoma, melanoma and pancreatic carcinoma reveals a snapshot of their genomic landscapes. Hum Mutat. 2009;30:E451-E459.

24. Curtin JA, Fridlyand J, Kageshita T, et al. Distinct sets of genetic alterations in melanoma. N Engl J Med. 2005;353:2135-2147.

25. Freedman JA, Tyler DS, Nevins JR, Augustine CK. Use of gene expression and pathway signatures to characterize the complexity of human melanoma. Am J Pathol. 2011;178:2513-2522.

26. Brennan CW, Verhaak RG, McKenna A, et al. The somatic genomic landscape of glioblastoma. Cell. 2013;155:462-477.

27. Toogood PL, Harvey PJ, Repine JT, et al. Discovery of a potent and selective inhibitor of cyclin-dependent kinase 4/6. J Med Chem. 2005;48:2388-2406.

28. Valkó K. Application of high-performance liquid chromatography based measurements of lipophilicity to model biological distribution. J Chromatogr A. 2004;1037:299-310.

29. Valkó K, Bevan C, Reynolds D. Chromatographic hydrophobicity index by fastgradient RP-HPLC: a high-throughput alternative to $\log$ P/log D. Anal Chem. 1997;69:2022-2029.

30. Schaer DA, Beckmann RP, Dempsey JA, et al. The CDK4/6 inhibitor abemaciclib induces a $\mathrm{T}$ cell inflamed tumor microenvironment and enhances the efficacy of PD-L1 checkpoint blockade. Cell Reports. 2018;22:2978-2994.

31. McCain J. First-in-class CDK4/6 inhibitor palbociclib could usher in a new wave of combination therapies for HR+, HER2- breast cancer. P\&T. 2015;40:511520 .

32. Knudsen ES, Witkiewicz AK. The strange case of CDK4/6 inhibitors: mechanisms, resistance, and combination strategies. Trends Cancer. 2017;3:39-55.

33. O'Leary B, Finn RS, Turner NC. Treating cancer with selective CDK4/6 inhibitors. Nat Rev Clin Oncol. 2016;13:417-430.

34. Pandey K, An HJ, Kim SK, et al. Molecular mechanisms of resistance to CDK4/6 inhibitors in breast cancer: a review. Int J Cancer. 2019;145:11791188

35. Herrera-Abreu MT, Palafox M, Asghar U, et al. Early adaptation and acquired resistance to CDK4/6 inhibition in estrogen receptor-positive breast cancer. Cancer Res. 2016;76:2301-2313.

36. Valeur E, Bradley M. Amide bond formation: beyond the myth of coupling reagents. Chem Soc Rev. 2009;38:606-631.

37. Carney B, Carlucci G, Salinas B, et al. Non-invasive PET imaging of PARP1 expression in glioblastoma models. Mol Imaging Biol. 2016;18:386-392.

38. O'Brien N, Conklin D, Beckmann R, et al. Preclinical activity of abemaciclib alone or in combination with antimitotic and targeted therapies in breast cancer. Mol Cancer Ther. 2018;17:897-907.

39. Hendricks JA, Keliher EJ, Marinelli B, Reiner T, Weissleder R, Mazitschek R. In vivo PET imaging of histone deacetylases by ${ }^{18} \mathrm{~F}$-suberoylanilide hydroxamic acid ( ${ }^{18}$ F-SAHA). J Med Chem. 2011;54:5576-5582. 